\title{
Osteointegração de osso bovino desvitalizado, hidroxiapatita de coral, poliuretana de mamona e enxerto autógeno em coelhos ${ }^{1}$
}

Devitalized bovine bone, porous coralline hydroxyapatite, castor beans polyurethane and autograft implants in rabbits

\author{
Arthur Silveira de Figueiredo ${ }^{2}$, Djalma José Fagundes ${ }^{3}$, Neil Ferreira Novo ${ }^{4}$, Celso \\ Massaschi Inouye ${ }^{5}$, Luiz Carlos Takita ${ }^{6}$, Maria Cristina Pita Sassioto ${ }^{7}$
}

1. Trabalho realizado na Disciplina de Cirurgia Experimental da Universidade Federal de Mato Grosso do Sul, pelo Programa de Pós-Graduação em Cirurgia e Experimentação da Universidade Federal de São Paulo Escola Paulista de Medicina (UNIFESP-EPM).

2. Chefe de Serviço de Ortopedia e Traumatologia da Universidade Federal de Mato Grosso do Sul (UFMS); Pós-Graduando em Cirurgia e Experimentação pela UNIFESP-EPM.

3. Coordenador do Programa de Pós-Graduação em Cirurgia e Experimentação da UNIFESP-EPM.

4. Professor Titular de da Disciplina de Bioestatística da UNIFESP-EPM.

5. Professor Titular do Departamento de Clínica Cirúrgica da UFMS.

6. Professor Adjunto de Anatomia Patológica da UFMS.

7. Professor Substituto de Propedêutica e Semiologia da UFMS.

\section{RESUMO}

OBJETIVO: Estudar comparativamente implantes de osso bovino desvitalizado, hidroxiapatita porosa de coral, poliuretana de mamona e enxerto ósseo autógeno no reparo de defeito ósseo de $6 \times 10 \mathrm{~mm}$ em fêmur de coelhos.

MÉTODOS: Noventa e seis coelhos Nova Zelândia distribuídos em 4 grupos conforme o material de preenchimento do defeito ósseo. Após seguimento de 4 e 12 semanas, as peças foram submetidas a análise macroscópica, microscópica, radiográfica, tomográfica e histométrica. Aos resultados aplicou-se testes estatísticos de Kruskal-Wallis, Mann-Whitney, Fisher, "t" de Student e quiquadrado.

RESULTADOS : O enxerto ósseo autógeno mostrou maior potencial osteogênico; o osso bovino desvitalizado produz maior reação inflamatória, maior número de cavidades císticas e lentidão de integração; a hidroxiapatita porosa de coral mantém a radiodensidade inicial; os implantes de osso bovino desvitalizado e poliuretana de mamona mostraram radiodensidades aumentadas conforme foram invadidos pelo tecido ósseo neoformado.

CONCLUSÃO: O implante de osso bovino desvitalizado induz reparação tecidual guiada mais lenta quando comparado ao enxerto ósseo autógeno e aos implantes de hidroxiapatita porosa de coral e poliuretana de mamona.

Descritores: Osso bovino. Hidroxiapatita. Polímero. Transplante autógeno. Coelhos.

\footnotetext{
ABSTRACT

PURPOSE: To study comparatively devitalized bovine bone, porous coralline hydroxyapatite, castor beans polyurethane implants and autograft in the repair of $6 \times 10 \mathrm{~mm}$ bony defect in femur of rabbits.
} 
METHODS: Ninety six New Zealand rabbits were distributed in 4 groups conforms the material of replacement of the bony defect. After following of 4 and 12 weeks, the pieces were submitted the macroscopic, microscopic, radiographic, tomographic and histometric analysis. To data was applied Kruskal-Wallis, Mann-Whitney, Fisher, t-Student and quisquare statistical tests.

RESULTS: The autograft showed greatest osteogenic potential; the devitalized bovine bone produces larger inflammatory reaction, larger number of cystic cavities and slowness integration; the porous coralline hydroxyapatite maintains the initial radiodensity; devitalized bovine bone and castor beans polyurethane implants showed increased radiodensities as they were invaded by the bony formation.

CONCLUSION: Devitalized bovine bone implants induces slower bony formation, when compared to the autograft, porous coralline hydroxyapatite and castor beans polyurethane implants.

Key words: Bovine bone. Hydroxyapatite. Polimer. Autograft. Rabbit.

\section{Introdução}

Na prática ortopédica freqüentemente encontra-se dificuldade de reparação de defeitos ósseos, quando o rápido crescimento de tecido conjuntivo no interior desses defeitos impede a formação de tecido ósseo, causando alterações anatômicas e perturbações funcionais e exigindo procedimentos operatórios reconstrutivos, que têm na enxertia óssea seu principal método de tratamento ${ }^{1}$.

O objetivo primário da enxertia óssea é o de preencher ou unir o defeito com material osteoindutivo e/ou osteocondutivo e o sucesso da enxertia depende da participação ativa do enxerto no processo da osteogênese reparativa ${ }^{2}$.

O osso autógeno é superior do ponto de vista da osteogênese e tem a vantagem adicional de não transmitir doenças infecto-contagiosas; mas possui limitações de uso, como quantidade insuficiente, quando a fonte doadora é escassa, como nas crianças e em pacientes já submetidos a cirurgias anteriores que exauriram áreas potencialmente doadoras de osso ${ }^{3,4,5,6}$.

A hidroxiapatita porosa de coral é uma cerâmica que tem como principais propriedades ser biocompatível, não tóxica, não carcinogênica, ter estabilidade química e biológica, e apresentar densidade, peso, resistência mecânica e elasticidade adequados ${ }^{6,7}$.

O osso bovino desvitalizado provê um arcabouço para as células fibroblásticas do osso hospedeiro invadirem e se diferenciarem em tecido cartilaginoso e ósseo e suas propriedades osteocondutivas podem ser melhoradas pela adição de fatores de crescimento ${ }^{8,9,10}$.

A poliuretana derivada do óleo de mamona é um poliéster formado por três moléculas do ácido ricinoleico, cada uma com um grupo hidroxila no carbono 12, propício para polimerização por meio de ligações uretana. A presença do radical amino na sua fórmula química lhe confere ação bactericida e a polimerização ocorre numa temperatura de aproximadamente $40^{\circ} \mathrm{C}$, compatível com a vida celular ${ }^{3,11,1^{3}}$.

A revisão bibliográfica não mostrou nenhum trabalho experimental publicado em nosso país ou na América Latina que comparasse o osso bovino desvitalizado, a hidroxiapatita porosa de coral, a poliuretana de mamona e o enxerto ósseo autógeno, em animal de experimentação, tornando pertinente este estudo comparativo. 


\section{Métodos}

Noventa e seis coelhos Nova Zelândia, albinos, machos, com idade média de cinco meses, peso médio de $2970 \mathrm{~g}$, provenientes do Biotério Central da UFMS, foram distribuídos em quatro grupos com 24 animais, de acordo com o preenchimento do defeito padrão: Grupo I enxerto ósseo autógeno, Grupo II - osso bovino desvitalizado, Grupo III - hidroxiapatita porosa de coral e Grupo IV - poliuretana de mamona. Os grupos foram divididos em subgrupos A (seguimento de 4 semanas) e B (seguimento de 12 semanas).

Os procedimentos operatórios foram realizados no Laboratório de Cirurgia Experimental do Departamento de Clínica Cirúrgica da UFMS. A proposta deste estudo foi submetida à apreciação e aprovação do Comitê de Ética em Pesquisa da UNIFESP-EPM, ratificadas pela Comissão de Pesquisa da Pró-Reitoria de Pesquisa e Pós-Graduação da UFMS.

Blocos quadrangulares de osso bovino desvitalizado e de hidroxiapatita porosa de coral foram recortados e modelados com broca odontológica em cilindros de $6 \mathrm{~mm}$ de diâmetro e $10 \mathrm{~mm}$ de comprimento.

A poliuretana de mamona foi preparada pela mistura manual do poliol $(20 \mathrm{~mL})$ com carbonato de cálcio $(20 \mathrm{~g})$ até sua homogeneização. Em seguida, o pré-polímero $(20 \mathrm{~mL})$ foi acrescentado, seguindo-se com a homogeneização da mistura. O compósito foi deixado em repouso, em temperatura ambiente, por quarenta minutos, adquirindo um estado plástico poroso. Com serra ortopédica oscilatória o bloco foi dividido em fragmentos quadrangulares, e com broca odontológica foram recortados e modelados em cilindros com $10 \mathrm{~mm}$ de comprimento e $6 \mathrm{~mm}$ de diâmetro.

Os cilindros foram vedados em embalagem plástica dupla, consecutivas, individuais, esterilizados por óxido de etileno e armazenados em temperatura ambiente até o momento da operação. Os procedimentos operatórios de confecção do defeito padrão e de seu preenchimento com enxerto autógeno ou implante de biomateriais seguiram método já padronizado ${ }^{6}$.

Após observação por período de 4 e 12 semanas, os coelhos receberam injeção intramuscular de pentobarbital sódico, na dose de $60 \mathrm{mg} . \mathrm{Kg}^{-1}$, promovendo eutanásia. Os membros posteriores foram desarticulados no quadril, os tecidos moles conectores com a tíbia seccionados e os fêmures dissecados com isolamento da área condilar do procedimento operatório.

$\mathrm{Na}$ análise macroscópica observou-se a coloração, textura e reparação da cortical óssea, além da mobilidade dos implantes. Os fêmures foram submetidos a radiografias em posicionamento crânio-caudal e látero-lateral, com observação da integridade óssea, desvio angular, formação óssea ectópica e consolidação óssea.

Ambos fêmures de seis animais do Subgrupo A e de dez animais do Subgrupo B foram sorteados e submetidos à tomografia axial computadorizada, em cortes tomográficos com $1 \mathrm{~mm}$ de espessura e ampliação das imagens em torno de 2,2 vezes para análise da integração óssea dos implantes. Baseando-se nas radiodensidades obtidas pela tomografia computadorizada, pontuou-se um escore máximo de 20 para o osso cortical, de 9 para o osso medular, de 0 a 1 para o tecido gorduroso, e de acordo com a maior ou menor capacidade de absorção dos raios-X dos seguimentos analisados nas áreas implantadas, pontuou-se escores intermediários nesta escala de valores (Quadro 1) 
QUADRO 1 - Escore, radiodensidade e desvio padrão das estruturas (anatômicas e implantes) quantificadas por tomografia computadorizada.

\begin{tabular}{|l|c|c|}
\hline \multicolumn{1}{|c|}{ Estrutura } & Escore & Radiodensidade \\
\hline Osso cortical do hospedeiro & $15-20$ & $2000 \pm 300$ \\
Hidroxiapatita porosa de coral & $12-15$ & $1200 \pm 100$ \\
Enxerto ósseo autógeno & $9-12$ & $900 \pm 200$ \\
Osso medular do hospedeiro & $5-9$ & $600 \pm 250$ \\
Osso bovino desvitalizado & $2-5$ & $200 \pm 150$ \\
Poliuretana de mamona & $1-2$ & $100 \pm 100$ \\
Tecido gorduroso & $0-1$ & $-100 \pm(-100)$ \\
\hline
\end{tabular}

Os fêmures foram processados histológicamente e nas imagens obtidas pela microscopia óptica foram observadas e quantificadas a reação inflamatória e a formação de tecido ósseo. Nos campos microscópicos da zona de transição do implante com o osso hospedeiro foi realizada a contagem de osteoblastos. Nas imagens captadas pela digitalização das lâminas histológicas calculou-se a o diâmetro, a densidade e a área física ocupada pelo implante.

Para análise estatística dos resultados, realizada pela Disciplina de Bioestatística do Departamento de Medicina Preventiva da UNIFESP-EPM, foram aplicados os testes de análise de variância para grupos independentes ${ }^{13,14}$ fixando-se em 0,05 ou $5 \%$ ? ? 0,05) o nível de rejeição da hipótese de nulidade.

\section{Resultados}

A evolução ponderal mostrou que todos coelhos ganharam peso, demonstrando que os procedimentos experimentais não interferiram no desenvolvimento dos animais.

Os resultados da observação macroscópica da coloração da cortical óssea mostraram uma maior alteração nos animais do grupo IV, no seguimento de 4 e 12 semanas, pelo fato da poliuretana de mamona ter, originalmente, uma cor amarelada que persistiu nos períodos seguimentos ( $\mathrm{Z}=10,91$ - Grupo IV < I, II e III).

A recuperação da textura lisa da cortical óssea foi significante nos grupos I e III com seguimento de 4 semanas, e no grupo I no seguimento de 12 semanas $\left(?^{2}=11,22\right.$ - Grupo I > II, III e IV).

No seguimento de 4 semanas, os animais dos grupos I e III apresentaram uma cicatrização cortical mais rápida que os animais dos grupos II e IV. No seguimento de 12 semanas os animais do grupo III apresentaram resultados semelhantes aos animais do grupo I, mostrando que o enxerto ósseo autógeno e a hidroxiapatita porosa de coral promovem uma osteogênese mais precoce $\left(?^{2}=15,19\right.$ - Grupo I e III < II e IV).

A observação radiográfica da presença de fratura femoral, não mostrou diferença significante entre os grupos estudados, o que parece ser resultante de uma técnica operatória pouco agressiva na confecção de um defeito padrão em dimensões que não provocam instabilidade óssea.

Os coelhos do grupo III mostraram uma maior presença de desvio em valgo do eixo femoral longitudinal no seguimento de quatro semanas, por possível lesão da cartilagem de crescimento femoral distal durante o procedimento operatório $\left(?^{2}=8,57\right.$ - Grupo III > I, II e IV).

A presença de formação óssea mais exuberante, ultrapassando os limites da cortical óssea, foi significante no grupo I, nos seguimentos de 4 e 12 semanas, demonstrando uma maior capacidade de osteoindução dos enxertos ósseos autógenos $\left(\right.$ ? $^{2}=10,43$ - Grupo I < II, III e IV). 
A análise estatística dos resultados da observação da radiodensidade dos implantes, por tomografia computadorizada, mostrou uma diferença significante dos animais do Grupo III, no seguimento de 4 e 12 semanas, resultante da maior radiodensidade original do próprio implante de hidroxiapatita porosa de coral, que se acentua com a invasão de seus poros pelo tecido ósseo neoformado (H=76,12 - Grupo III > I, II e IV) (Figura 1).

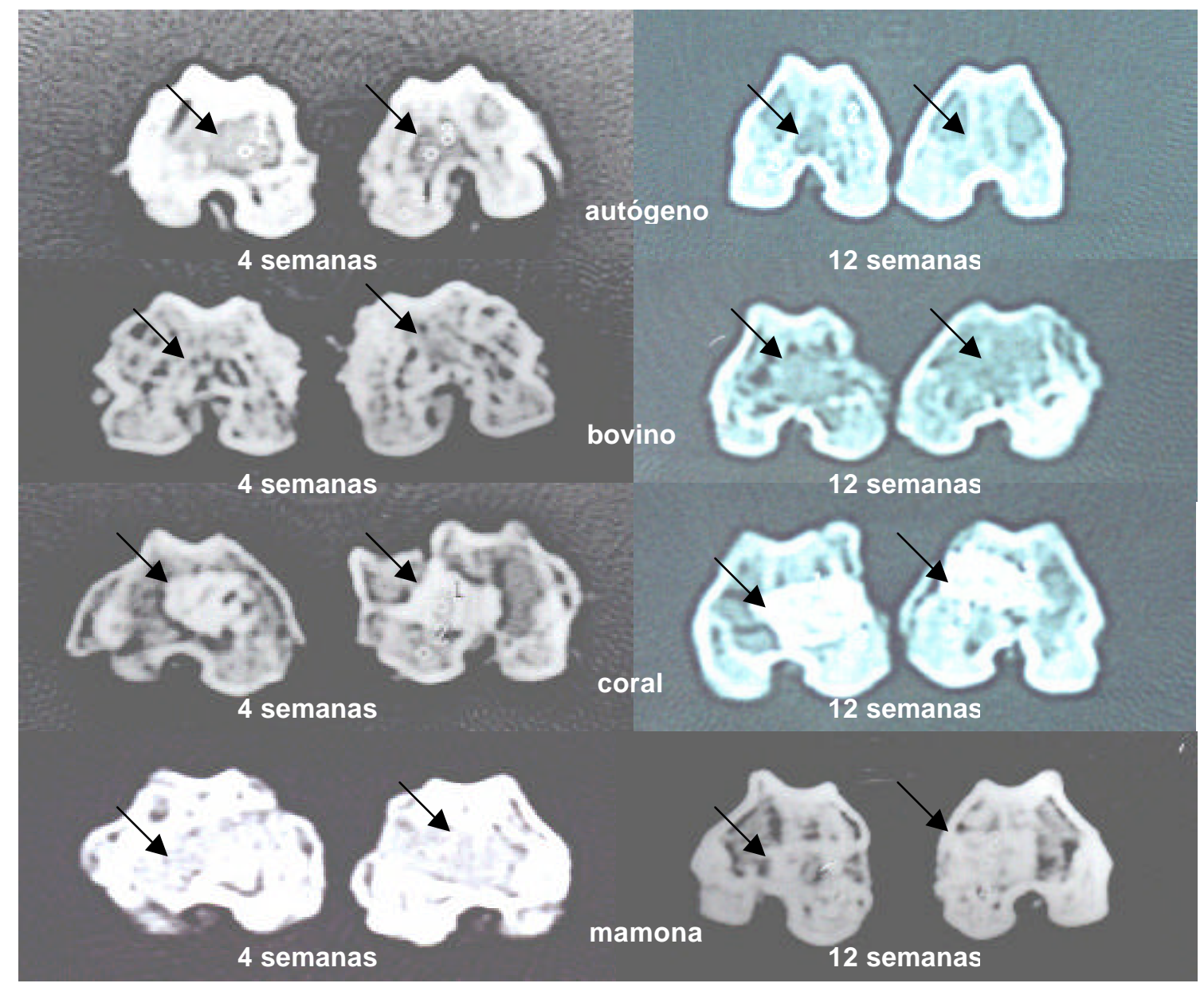

FIGURA 1 - Fotografia mostrando o aspecto da radiodensidade do osso condilar e dos implantes (setas), observados pela tomografia computadorizada.

Os resultados da observação microscópica mostraram uma presença significante de cavidades císticas nos coelhos dos grupos II, III e IV no seguimento de 4 e 12 semanas, com ausência das mesmas nos animais do grupo I. As cavidades são, possivelmente, resultantes de uma ação osteoclástica mais intensa pela presença de implantes não vascularizados, interpretados pelo tecido receptor como corpos estranhos $\left(?^{2}=43,51\right.$ - Grupo I < II, III e IV).

Observou-se uma diferença significante da presença de tecido ósseo maduro nos animais do grupo I no seguimento de 4 semanas e nos animais dos grupos I e III no seguimento de 12 semanas. Tal fato encontra explicação na característica da matriz óssea dos enxertos ósseos autógenos agir como indutora da neoformação óssea pela transformação dos fibroblastos ou células mesenquimais locais, em osteoblastos que, por sua vez, utilizam a hidroxiapatita presente para formar osso novo $\left(?^{2}=21,37\right.$ - Grupo II $<$ I, III e IV $)$.

A análise estatística dos resultados da quantificação da reação inflamatória na zona de transição entre o enxerto/implante e o osso receptor, por programa informatizado, mostrou diferença significante nos animais do grupo II no seguimento de 4 e 12 semanas. Baseando-se nestes resultados pode-se afirmar que o osso bovino desvitalizado, quando comparado aos 
demais implantes, é o que provoca maior reação inflamatória local com retardo no processo de consolidação óssea (H=88,97 - Grupo I < II, III e IV).

Os resultados da quantificação do tecido ósseo neoformado na zona de transição entre o enxerto/implante e o osso receptor, mostraram diferença significante entre o grupo I e os demais grupos no seguimento de 4 e 12 semanas, decorrente de osteogênese precoce promovida pelos enxertos ósseo autógenos (H=86,30 - Grupo I > II, III e IV) (Figuras 2 e 3).
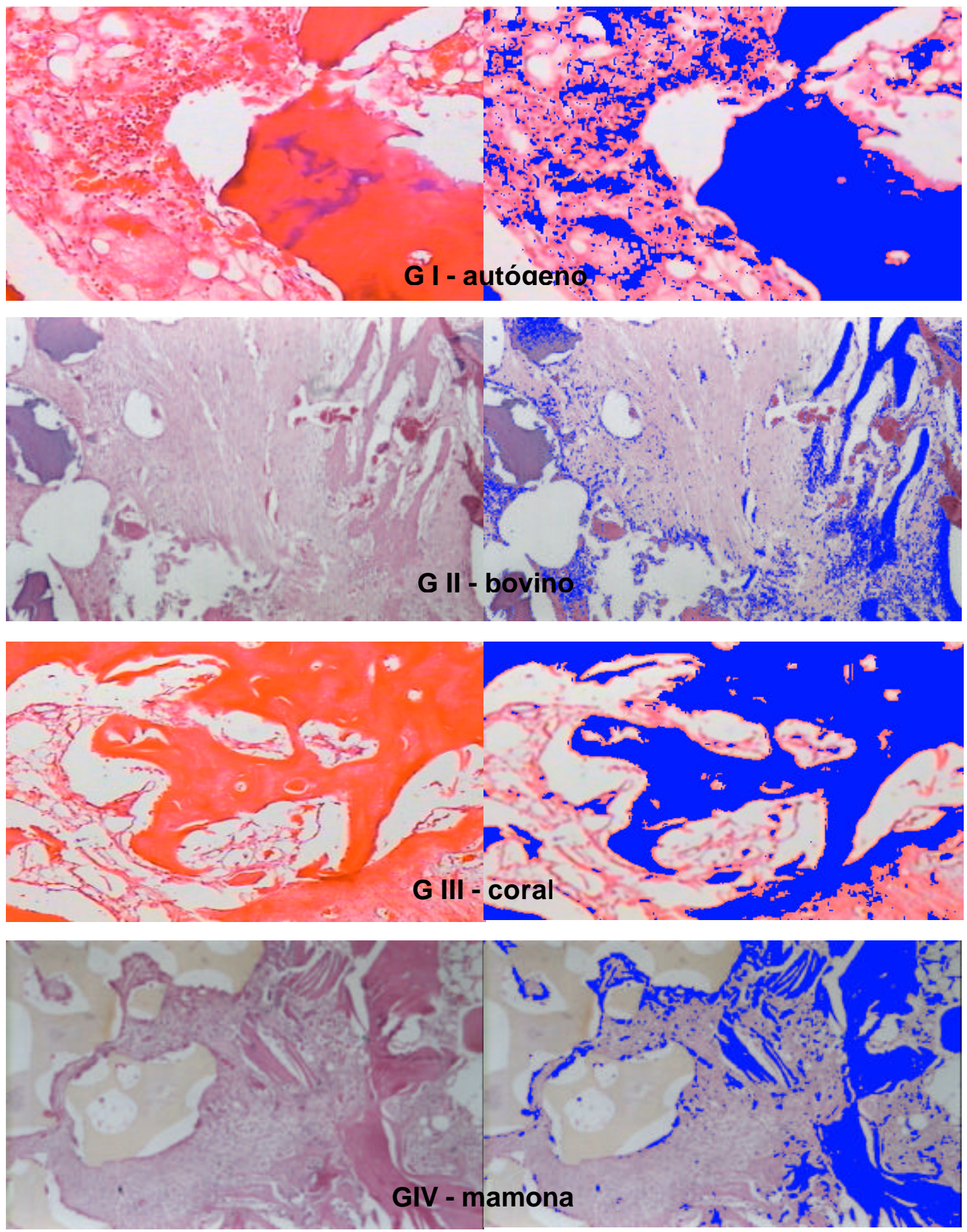

FIGURA 2 - Fotomicrografias mostrando a presença e quantificação do tecido ósseo neoformado (áreas em azul) em côndilos femorais, com seguimento de 4 semanas. HE (10x). 

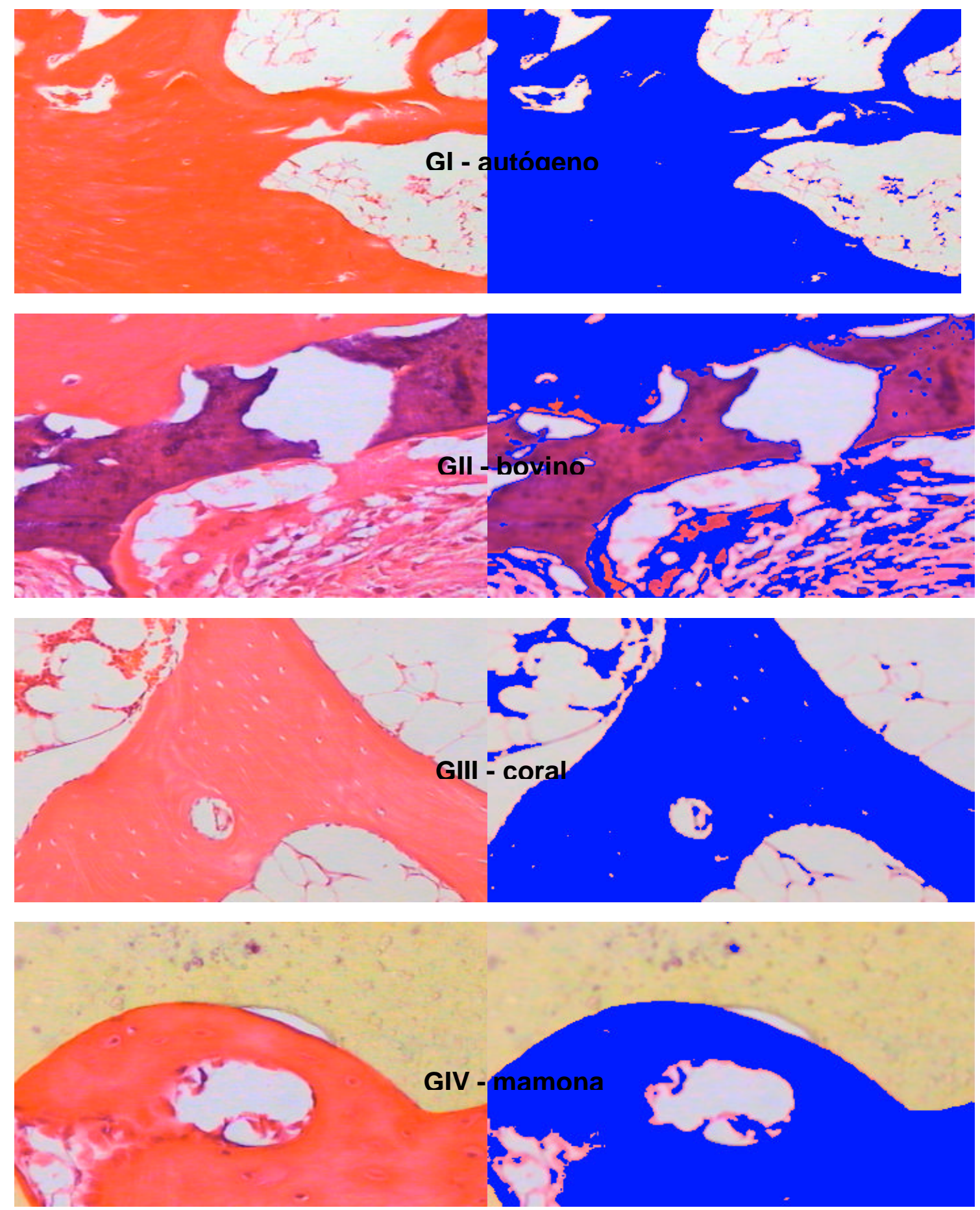

FIGURA 3 - Fotomicrografias mostrando a presença e quantificação do tecido ósseo neoformado (áreas em azul) em côndilos femorais, com seguimento de 12 semanas. HE (10x).

No seguimento de 4 semanas foi observado maior quantidade de osteoblastos na zona de transição entre o enxerto/implante o osso receptor nos animais dos Grupos I, e menor quantidade dessas células nos animais do Grupo II, mostrando que os enxertos ósseos autógenos desencadeiam o processo de osteogênese mais precocemente e, que os implantes de osso bovino desvitalizado necessitam de maior período de tempo para início do processo 
osteogênico, quando comparados com os implantes de hidroxiapatita porosa de coral e poliuretana de mamona (H=74,44 - Grupo I < II, III e IV).

Os resultados da quantificação da área física ocupada pelos implantes mostraram uma redução significante das áreas ocupadas pelos implantes do grupo II, no seguimento de 4 semanas ( $\mathrm{F}=$ $28,80)$, com redução também significante no seguimento de 12 semanas $(F=40,45)$, que foi interpretada como resultante de uma maior atividade osteoclástica na zona de transição entre o implante e o osso receptor ( $\mathrm{F}=40,45$ - Grupo II < III e IV) (Figura 4). A mensuração do menor diâmetro dos implantes mostrou diferença significante do grupo III nos seguimentos de 4 e 12 semanas $(\mathrm{F}=20,32$ - Grupo II > III).

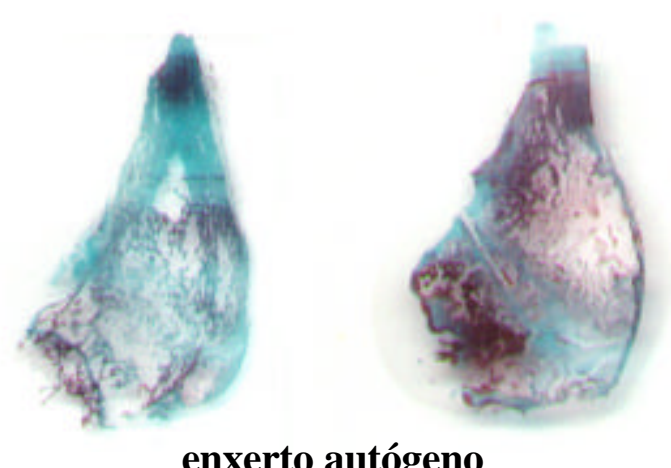

enxerto autógeno

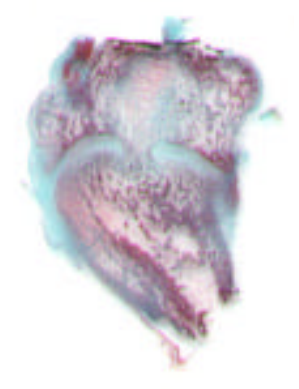

hidroxianatita de coral

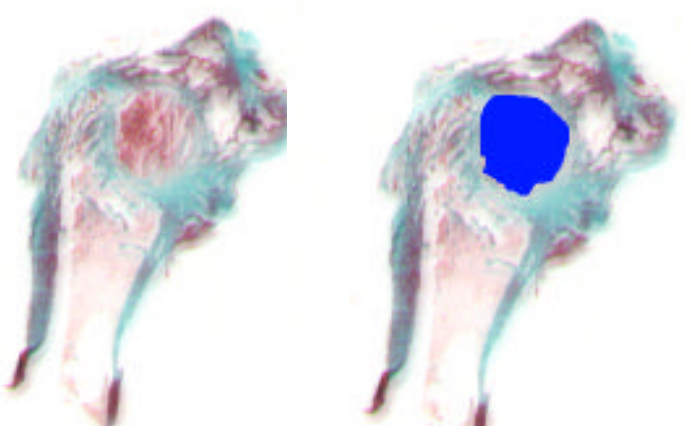

matriz hovina

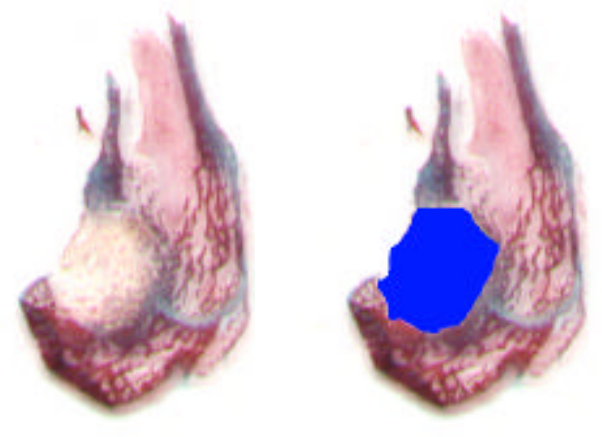

noliuretana de mamona

FIGURA 4 - Fotografia das imagens digitalizadas das lâminas histológicas dos côndilos femorais com seleção da área (em azul) ocupada pelos implantes nos diversos grupos de estudo, com seguimento de 12 semanas. No Grupo I não se visibilizou a área de transição entre o enxerto ósseo autógeno e o osso receptor.

\section{Discussão}

A retirada do enxerto ósseo autógeno implica em aumento do tempo operatório, maior perda sangüínea, ferida operatória adicional e conseqüente aumento da morbidade ${ }^{1}$. A busca de outros materiais implica, também em limitações logísticas como relação custo/benefício, facilidade de obtenção, disponibilidade de fonte doadora, local apropriado e tempo disponível para o tratamento ${ }^{2}$.

Um biomaterial de uso a ser proposto é a matriz óssea desvitalizada, como uma possível solução para situações clínicas que exijam o reparo de defeitos ósseos, por possuir propriedades osteocondutivas que estimulam a neoformação e aposição óssea em sua periferia e interior, fixando-se firmemente às paredes de defeitos padrão ${ }^{4,10}$. 
A hidroxiapatita porosa de coral é uma cerâmica biocompatível, biodegradável, anisotrópica, inerte e atóxica que provê uma estrutura para a invasão do tecido receptor, podendo ser produzida no tamanho e na quantidade desejadas, recortada, esterilizada e estocada por longos períodos em temperatura ambiente ${ }^{15,16}$.

A poliuretana de mamona, um polímero vegetal biocompatível e atóxico, utilizado na clínica ortopédica como cimento ósseo nas artroplastias, proporcionando uma fixação firme ao osso por uma massa pouco porosa. Em função desta característica, preparou-se o polímero vegetal adicionado com carbonato de cálcio com o duplo propósito de conferir-lhe maior porosidade e visibilidade aos raios $X^{17}$. Para evitar a diminuição da massa superficial do polímero, descrita como "compactação" da massa polimérica, que ocasionaria perda do ajuste do implante às paredes do defeito-padrão, optou-se por permitir a polimerização da poliuretana fora do defeito padrão. Exposta ao meio ambiente, a poliuretana de mamona mostrou aumento de sua porosidade, condição necessária para facilitar a invasão do implante pelo tecido ósseo neoformado $^{18}$.

Selecionou-se o coelho como animal de experimentação por ser de fácil obtenção e manuseio, e por ser o menor mamífero com dimensões femorais suficientes para o estudo dos implantes nas dimensões pré-determinadas em estudo piloto. A região metáfiso-epifisária do fêmur foi escolhida pela facilidade e simplicidade do acesso operatório, e pela quantidade de osso esponjoso necessária ao estudo comparativo proposto, baseando-se em Figueiredo e col. ${ }^{6}$.

Foram utilizados animais de mesma raça, sexo e idade para homogeneização da amostra e sua divisão em grupos e subgrupos teve a finalidade de permitir os seguimentos em relação ao tempo e adequada aplicação dos testes estatísticos.

Preferiu-se o processo de esterilização dos implantes com óxido de etileno, que se mostrou eficaz, não levando a alteração do aspecto físico, em concordância com os achados de Ohara e col. ${ }^{12}$. O processo de esterilização por autoclavagem, promove uma significante redução da resistência mecânica dos implantes de osso bovino, conforme relato de Viceconti e col ${ }^{19}$.

Nos coelhos utilizados em pesquisa, a anestesia é considerada um fator limitante, em virtude dos animais apresentarem instabilidade dose-resposta aos agentes anestésicos e dificuldades em manter o plano anestésico. O procedimento anestésico seguiu as orientações de Fonseca e col. $^{20}$ e transcorreu sem incidentes com o uso da associação de quetamina (sedativo e analgésico) com a xilazina (hipnótico não-narcótico e relaxante muscular). A manutenção do plano anestésico efetivo foi em torno de 60 minutos, tempo este suficiente para a realização dos procedimentos operatórios, que duraram em média 45 minutos.

No modelo experimental escolhido, no momento da confecção do defeito padrão, optou-se pela não ressecção do periósteo no local de posicionamento da trefina, apesar do conhecimento da grande capacidade osteogênica que este tecido possui, e que pode ser responsabilizada pela formação óssea ectópica presente em todos os grupos de estudo.

Para evitar necrose celular nas paredes do defeito padrão, utilizou-se um perfurador elétrico de baixa rotação. Este fato foi observado por Ignácio e col. ${ }^{11}$, que relataram necrose térmica das células ósseas, na zona de transição implante-osso receptor, provocada por perfurador elétrico de alta rotação, prejudicando a possível consolidação.

A escolha do enxerto a ser utilizado é decisivamente influenciada pela estabilidade do leito receptor. Nos casos de defeitos estáveis, como os defeitos ósseos criados experimentalmente, os enxertos não necessitam oferecer nenhuma estabilidade adicional ou receber nenhum tipo de fixação interna ou externa ${ }^{6,10}$.

Os implantes utilizados, por terem as mesmas dimensões dos defeitos padrões, tiveram firme estabilidade marginal, não necessitando fixação adicional. A análise estatística dos resultados da observação de mobilidade dos enxertos e dos implantes não mostrou diferenças significantes nos diversos grupos estudados. 
Com relação às observações radiográficas, ressalta-se as inúmeras tentativas de se manter um posicionamento padronizado dos fêmures, em ântero-posterior e látero-lateral, o que não foi possível em função do arqueamento natural desta espécie animal. Considerou-se sinal radiográfico de consolidação a ausência de halo de radiotransparência circunjacente aos enxertos ou implantes. Os resultados mostraram uma diferença significante do grupo I no seguimento de 4 e 12 semanas, demonstrando ser a consolidação óssea um aspecto tempodependente e que os métodos radiográficos convencionais são, por si só, insuficientes para a determinação fidedigna da consolidação em ossos, e calos ósseos, de pequenas dimensões ${ }^{3}$.

Branemark e col. ${ }^{21}$ estudando a osteointegração de implantes dentais encontrou dificuldades no planejamento operatório. $\mathrm{O}$ fato das imagens radiográficas convencionais serem bidimensionais, não permitiu avaliação fidedigna da qualidade e quantidade do tecido ósseo na área de interesse. Para suprir as necessidades de planejamento e controle pós-operatório, passaram a utilizar a tomografia computadorizada, que usa os raios- $\mathrm{X}$ da mesma forma que as radiografias convencionais, mas, ao invés de uma projeção simples, ela combina matematicamente centenas de projeções, formando uma imagem sem distorções, num único plano, que geralmente, é transverso ao eixo longitudinal corporal.

A imagem obtida pela tomografia computadorizada é um mapa do pixel do coeficiente de atenuação do tecido em imagem linear obtida pelos raios-X dentro de um plano; esse coeficiente de atenuação é proporcional à densidade do tecido e também depende de um cálculo complexo utilizando números atômicos. A tomografia computadorizada converte o coeficiente de atenuação linear para uma escala numérica, o escore de Hounsfield, podendo discernir tecidos com uma diferença de atenuação menor que $1 \%$ ou poucos pontos da escala de Hounsfield.

Considerando ser a tomografia computadorizada um exame de alto custo operacional, optouse pela redução do número de animais estudados, porém, com realização dos exames em todos os grupos e subgrupos estudados, compondo uma amostra suficiente para a execução de uma análise estatística confiável. Os resultados do escore de Hounsfield para os valores da radiodensidade das áreas de interesse nos côndilos femorais mostraram que os animais de todos os grupos apresentaram um aumento significante da radiodensidade nos seguimentos de 4 e 12 semanas, decorrente da invasão dos implantes pelo tecido ósseo neoformado, demonstrando não haver vantagem na utilização da tomografia computadorizada na comparação de implantes com alta radiodensidade original.

$\mathrm{Na}$ biopatologia dos osteoclastos, que são formados pela fusão de células mononucleares, uma vez iniciada sua atividade de reabsorção pela presença de elementos estranhos ao tecido, ocorre a formação de cavidades císticas com resíduos desses elementos em seu interior ${ }^{22}$.

A aquisição, processamento e análise de imagens têm sido utilizadas como uma ferramenta indispensável de auxílio às pesquisas, permitindo ao pesquisador determinar inúmeras variáveis tais como a área, perímetro, número de estruturas e fator de forma da estrutura (absorção de luz, maior e menor diâmetro, distância entre dois pontos, cálculo de ângulos e coordenada do centro de massa), de uma maneira fácil, rápida e precisa; permitindo ainda que os dados de imagens adquiridas possam ser armazenados, impressos ou exportados para outros programas, permitindo uma eficiente e completa documentação ${ }^{23,24}$.

De acordo com Weiler e col. ${ }^{25}$ e Quinn e col. ${ }^{26}$, as alterações da superfície podem estar relacionadas a uma interação dos materiais dos implantes com o organismo. Vários mecanismos foram apontados como os responsáveis pela biodegradação, sendo os principais a hidrólise e a oxidação, onde participariam os fluidos orgânicos, agentes oxidativos liberados pelos macrófagos e células gigantes.

A maior densidade da poliuretana de mamona no seguimento de 4 semanas foi atribuída à sua menor porosidade. No seguimento de 12 semanas a hidroxiapatita porosa de coral mostrou maior densidade, talvez pela maior invasão de tecido ósseo neoformado em sua rede de poros. 
Holmes e col. ${ }^{27}$ observaram pela microscopia eletrônica que a hidroxiapatita porosa de coral após implantação óssea tinha $84 \%$ da área com densidade maior que a do osso, e que os $16 \%$ restantes eram representados pelas lacunas, canais e espaços fibrovasculares.

Analisando os dados expostos e sabendo que o melhor implante é aquele que provoca menor reação inflamatória e permite maior invasão de tecido ósseo dentro e fora de sua estrutura num período de tempo mais curto, pode-se deduzir que o enxerto ósseo autógeno produz menor reação inflamatória que os demais implantes estudados, com presença de células gigantes tipo corpo estranho, sem formação de cavidades císticas, e cria as condições necessárias a uma osteogênese reparativa mais precoce.

O osso bovino desvitalizado apesar da maior reação inflamatória com presença de células gigantes tipo corpo estranho, formação de cavidades císticas com resíduos do implante em seu interior e invasão mais lenta dos poros pelo tecido ósseo, em comparação com os demais implantes, mostrou propriedades osteocondutivas na reparação de defeitos ósseos.

A hidroxiapatita porosa de coral mostrou maior eficácia na promoção da osteogênese, com presença de menor reação inflamatória que os implantes de poliuretana de mamona e osso bovino desvitalizado, porém mostrou-se menos eficaz que o enxerto ósseo autógeno.

A poliuretana de mamona mostrou maior propriedade osteocondutiva e menor reação inflamatória que o osso bovino desvitalizado, com invasão de seus poros e preenchimento das cavidades císticas por tecido ósseo, mostrando-se eficaz como arcabouço para a reparação tecidual guiada.

A observação radiográfica mostrou que a presença do halo de radiotransparência circunjacente ao enxerto/implante é um aspecto eficaz na avaliação da consolidação óssea. A alta radiodensidade inicial da hidroxiapatita porosa de coral, comprometeu o estudo comparativo entre os implantes, devendo novas pesquisas ser desenvolvidas na procura da melhor alternativa de avaliação por imagem da integração óssea utilizando biomateriais.

A digitalização das lâminas histológicas, permitindo a visibilização direta da peça óssea, mostrou-se eficaz para quantificação da área ocupada pelo biomaterial, assim como da alteração de sua forma por reabsorção ou ação de forças compressivas.

Considerando-se os aspectos morfológicos comparados nos períodos de estudo, as limitações devidas aos métodos empregados e os resultados obtidos, pode-se deduzir que houve osteogênese necessária à recuperação da integridade mecânica e fisiológica do osso, com todos os materiais estudados. Novas pesquisas deverão ser realizadas, no futuro, para averiguar outros fatores que influenciem o processo de reparação tecidual guiada na presença de enxerto ósseo autógeno, osso bovino desvitalizado, hidroxiapatita porosa de coral e poliuretana de mamona.

\section{Conclusão}

O implante de osso bovino desvitalizado produz maior reação inflamatória, maior formação de cavidades císticas e reparação tecidual guiada mais lenta, quando comparado ao enxerto ósseo autógeno e aos implantes de hidroxiapatita porosa de coral e poliuretana de mamona.

\section{Referências}

1. Eggers C, Meeder PJ. Biological principles of autogenous bone grafting. Injury 1994; 25(Supl. 1):17-20.

2. Nade S. Stimulating osteogenesis. Injury 1994; 25:577-83.

3. Silva MJA, Tavano O, Guimarães SAC, Gomes MF. Estudo do comportamento do tecido ósseo frente ao implante do polímero de mamona em rádios de coelhos, pela análise quantitativa das radiopacidades nas imagens radiográficas convencionais. Rev FOB 1997; 5:69-77.

4. Aichelmann-Reidy ME, Yukna RA. Bone replacement grafts: the bone substitutes. Dent Clin North Am 1998; 42(3):491-503. 
5. Martinez SA, Walker T. Bone grafts. Vet Clin North Am Small Anim Pract 1999; 29(5):1207-19.

6. Figueiredo AS, Takita LC, Goldenberg S. Comparação entre a hidroxiapatita porosa de coral e o enxerto ósseo autólogo em coelhos. Acta Cir Bras 1998; 12(2):84-8.

7. Bernard SL, Picha GJ. The use of coralline hydroxyapatite in a "biocomposite" free flap. Plastic Reconst Surg 1991; 87:96-105.

8. Yoshikawa T, Ohgushi H, Nakajima H, Yamada E, Ichijima K, Tamai S, Ohta T. In vivo osteogenic durability of cultured bone in porous ceramics: a novel method for autogenous bone graft substitution. Transplantation 2000; 69(1):128-34.

9. Macedo CAS, Galia CR, Silva ALB, Cesar PC, Sanches PRS, Duarte LS. Comparação da resistência à compressão do osso bovino congelado e liofilizado. Rev Bras Ortop 1999; 34(9):529-34.

10. Berglundh T, Lindhe J. Healing around implants placed in bone defects treated with Bio-Oss: an experimental study in the dog. Clin Oral Impl Res 1997; 8:117-24.

11. Ignácio $\mathrm{H}$, Mazzer N, Barbieri $\mathrm{CH}$, Chierici G. Uso da poliuretana derivada do óleo de mamona para preencher defeitos ósseos diafisários segmentares do rádio. Estudo experimental em coelhos. Rev Bras Ortop 1997; 32:815-21.

12. Ohara GH, Kojima KE, Rossi JC, Telles M, Soares TVC, Salomão C. Estudo experimental da biocompatibilidade do polímero poliuretano da mamona implantado intra-óssea e intra-articular em coelhos. Acta Ortop Bras 1995; 3(2):62-8.

13. Siegel S, Castellan Jr NJ. Nonparametric statistics. New York: McGraw-Hill; 1988.

14. Sokal RR, Rohlf FJ. Biometry. New York: WH Freeman; 1969.

15. Bucholz RW, Carlton A, Holmes R. Interporous hydroxyapatite as a bone graft substitute in tibial plateau fractures. Clin Orthop Rel Res 1980; 240:53-62.

16. Light M, Kanat IO. The possible use of coralline hydroxyapatite as a bone implant. J Foot Surg 1991; 30(5):472-6.

17. Carvalho TLL, Araújo CACA, Teófilo JM, Brentegani LG. Histologic and histometric evaluation of rat alveolar wound healing around polyurethane resin implants. Int J Oral Maxillofac Surg 1997; 26:149-52.

18. Ignácio H. Utilização do cimento derivado do polímero da mamona no preenchimento de falha óssea: estudo experimental em coelhos [Tese - Mestrado]. Ribeirão Preto: Universidade de São Paulo; 1995.

19. Viceconti M, Toni A, Brizio L, Rubbini L, Borrelli A. Effetto dell'autoclavaggio sulle proprietà meccaniche dell'osso bovino di banca. Chir Organi Mov 1996; 81:63-8.

20. Fonseca NM, Goldenberg S, Gomes PO, Lima CAL. Anestesia em coelhos. Acta Cir Bras 1996; 11:82-104.

21. Branemark PI, Hanson BO, Adell R. Using CT and Simplant to plan implant therapy. 2001. Disponível em URL: http://www.simplant.com/articles/omega.html .

22. Chambers TJ. The pathobiology of the osteoclast. J Clin Pathol 1985; 38:241-52.

23. Tognini JRF. Estudo biomecânico e morfológico da cicatrização da parede abdominal de ratos sob ação de meloxicam [Tese - Doutorado]. Universidade Federal de São Paulo; 1999.

24. Gatti Neto AG, Borra RC, Novelli MD, Silveira FRX. Computerized photometric analysis of cystic lesions from panoramic radiographies. J. Dent Res 1996; 75(5):1096-9.

25. Weiler A, Hoffmann RFG, Stähelin AC, Helling HJ, Südkamp NP. Biodegradable implants in sports medicine: the biological base. J Arthroscop Rel Surg 2000; 16(3):305-21.

26. Quinn J, Sabokbar A, Athanasou NA. Cells of the mononuclear phagocytes series differentiate into lacunar bone-resorbing cells. J Pathol 1995; 179:106-11.

27. Holmes RE, Bucholz RV, Mooney V. Porous hydroxyapatite as a bone-graft substitute in metaphyseal defects. J Bone Joint Surg 1986; 68-A:904-11.

Correspondência:

Dr. Arthur Silveira de Figueiredo

Rua Barão do Rio Branco, 2167

79008-067 Campo Grande - MS

Tel: (67)325-8775

Fax: (67)321-0453

xxaxxi@brturbo.com

Recebimento: 15/04/2004

Revisão: 21/05/2004

Aprovação: 08/06/2004

Conflito de interesse: nenhum

Fonte de financiamento: nenhuma 
Como citar este artigo:

Figueiredo AS, Fagundes DJ, Novo NF, Inouye CM, Takita LC, Sassioto MCP. Osteointegração de osso bovino desvitalizado, hidroxiapatita de coral, poliuretana de mamona e enxerto ósseo autógeno em coelhos. Acta Cir Bras [serial online] 2004 Jul-Ag;19(4). Disponível em URL: $\underline{\text { http://www.scielo.br/acb. [também em CD-ROM]. }}$ 